\title{
Thermal Environment and Aeroheating Mechanism of Protuberances on Mars Entry Capsule
}

\author{
Miao Wenbo $\mathbb{D}^{1,2}{ }^{1,2}$ Qi ${ }^{3}{ }^{3}$ Li Junhong, ${ }^{1,2}$ Zhou Jingyun, ${ }^{1}$ and Cheng Xiaoli ${ }^{1,2}$ \\ ${ }^{1}$ China Academy of Aerospace Aerodynamics, PO BOX 7201, Sub PO BOX 16, Beijing 100074, China \\ ${ }^{2}$ Key Laboratory of Aero-Thermal Protection of Aerospace Vehicles, China Aerospace Science and Technology Corporation, \\ Beijing 100074, China \\ ${ }^{3}$ Beijing Institute of Spacecraft System Engineering, China
}

Correspondence should be addressed to Miao Wenbo; tingles@126.com

Received 12 August 2021; Accepted 9 October 2021; Published 20 November 2021

Copyright (C) 2021 Miao Wenbo et al. Exclusive Licensee Beijing Institute of Technology Press. Distributed under a Creative Commons Attribution License (CC BY 4.0).

\begin{abstract}
Mars has only thin atmosphere composed mainly of carbon dioxide that differs significantly from the atmosphere of Earth in terms of characteristics of reentry flows. To connect with the orbiter, the Mars entry capsule is provided with titanium pipes and other units installed on the heat-shield. These units will create significant local interaction flow on the surface of the capsule and cause additional heating on the surface of the shield during the entry of the capsule. With a view to interaction thermal environment issues for the surface of the shield, in this paper, the characteristics of protrusion interaction flow on different location of the shield were studied by means of numerical simulation. Heating mechanisms of protuberances on different location were derived by analyzing characteristic parameters such as local flow velocity, pressure, and Mach number. The results show that the interaction thermal environment of protuberances in the windward area is smaller than that of protuberances in the leeward area, mainly because subsonic flow dominates in the windward area, and the interaction is weak, while in the leeward area, the direction of flow intersects with protuberances to form a boundary layer shear flow, which results in a stronger interaction before the protuberances.
\end{abstract}

\section{Introduction}

Mars is a planet that has the most Earth-like natural environment currently explored by scientists. To adapt to the reentry environment of Mars, the capsule normally selects blunt body appearance, and the heat shield is subject to the most crucial aeroheating in the Mars entry. During the entry, the shield will retain mechanisms connected to the orbital module such as titanium pipes and other units. These units form a protrusion on the surface of the shield, which creates a complex interaction thermal environment on the shield, thus producing additional aeroheating on the surface of the shield and seriously affecting the performance of the thermal protection system.

Researches on protrusion interaction thermal environment have long been carried out. When protuberances present on the surface of the vehicle, hypersonic inflow will create a detached shock wave in front of protuberances, which interacts with boundary layers to generate complex shock wave-shock wave interaction around the protuberance that leads to the separation and reattachment of flow, causing additional interaction heating. Back in the early 1970s, Hung et al. [1, 2] classified and studied protrusion interaction. Based on the relationship between the height of protuberances and thickness of boundary layers, they divided the protrusion into high column and short column for theoretical analysis and research and gave a rough distribution diagram of the interaction flow. In addition to theoretical analysis means, experimental research was realized to some extent. Holden [3] roughly defined the range of the interaction area of protuberances (about 2-3times the diameter of the cylinder). Suxun [4] conducted experimental research on the thermal environment profile of circular cylinder, rectangular cylinder, compression corner, double ellipsoid, and other flows and realized the mechanism of protrusion interaction thermal environment. With the development of computer technology, numerical simulation has gradually become an important means for studying the interaction 


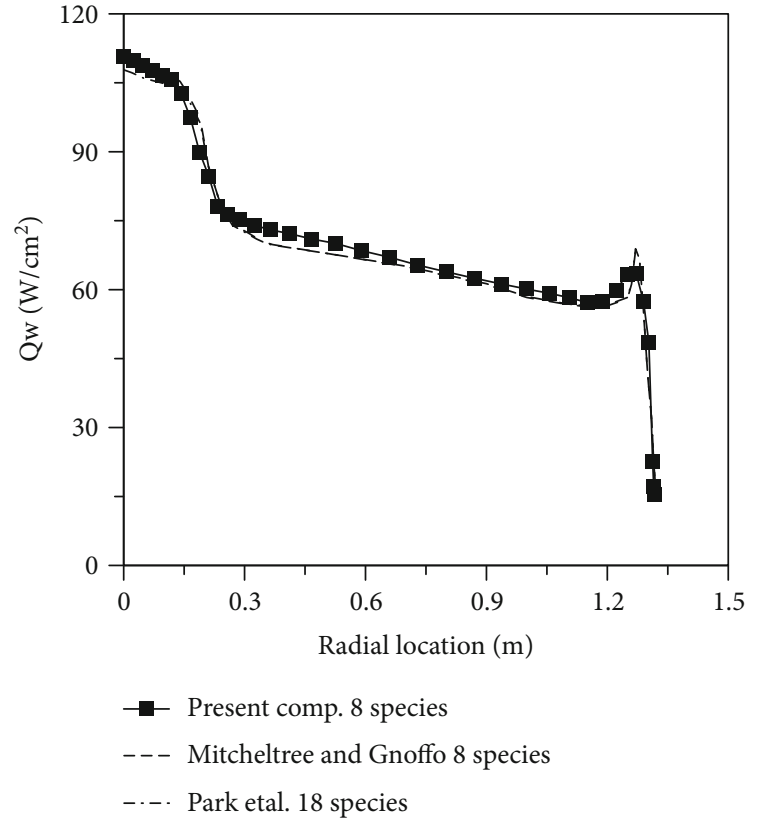

FIgure 1: Comparison of radial distributions of heat flux on the shield of the Mars capsule.

thermal environment of protuberances. Pan [5] investigated the scope of influence of the protrusion and the thermal environment of its interaction region through combination of theoretical analysis and numerical simulation and derived the quantitative relationships between the range of separation regions and the geometrical characteristics of protuberances. Fuqun [6] researched the interaction thermal environment of two types of typical protuberances-protrusions with a single trapezoidal cross-section and conical bosses and discovered that the protrusion interaction thermal environment of the conical boss is much bigger than that of the protuberance with a single trapezoidal cross-section. The developed numerical technology provides strong support for the predication of protrusion interaction thermal environment and is also applied in the prediction of thermal environment and thermal protection system design. Current theoretical analysis and experimental research are mainly concentrated in protrusion interaction analysis for simple flow (flat-plate/slender body). Despite allowing for simulation of complex flows, numerical simulation now mainly takes Earth's atmosphere as principal subject of research, and there are few studies on the thermal environment disturbed by protrusions in the Mars entry.

The atmosphere of Mars is mainly comprised of carbon dioxide and about 100 times thinner than Earth's. Compared with entry of Earth, Reynolds number for Mars entry is smaller when flying at high speed due to the low density of its atmosphere, and the characteristics of boundary layer of Mars Lander are different from those of Earth's. Pertinent researches should be carried out on the protrusion interaction in the entry of Mars considering the differences of thermo-chemical properties between $\mathrm{CO}_{2}$ and air in Earth. The aeroheating mechanism of protrusion interaction on the surface of shield is studied in this article and numerical

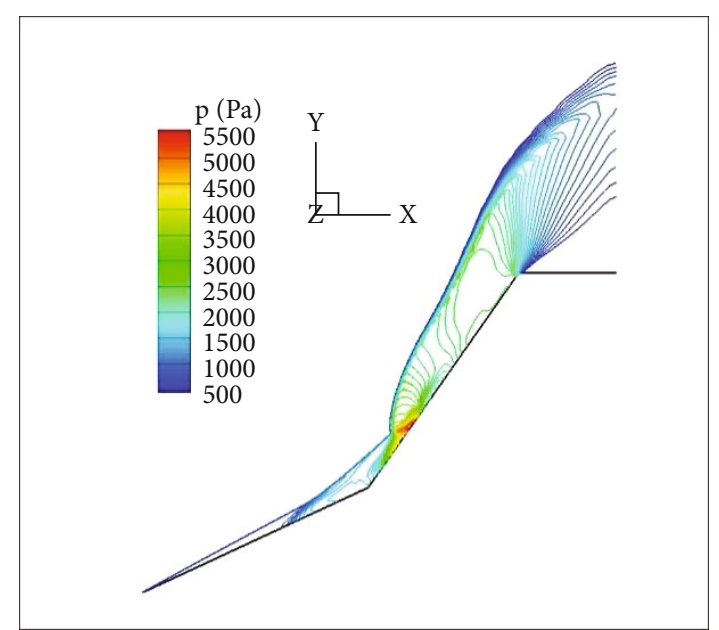

FIgURE 2: Contours of temperature and pressure at plane of symmetry.

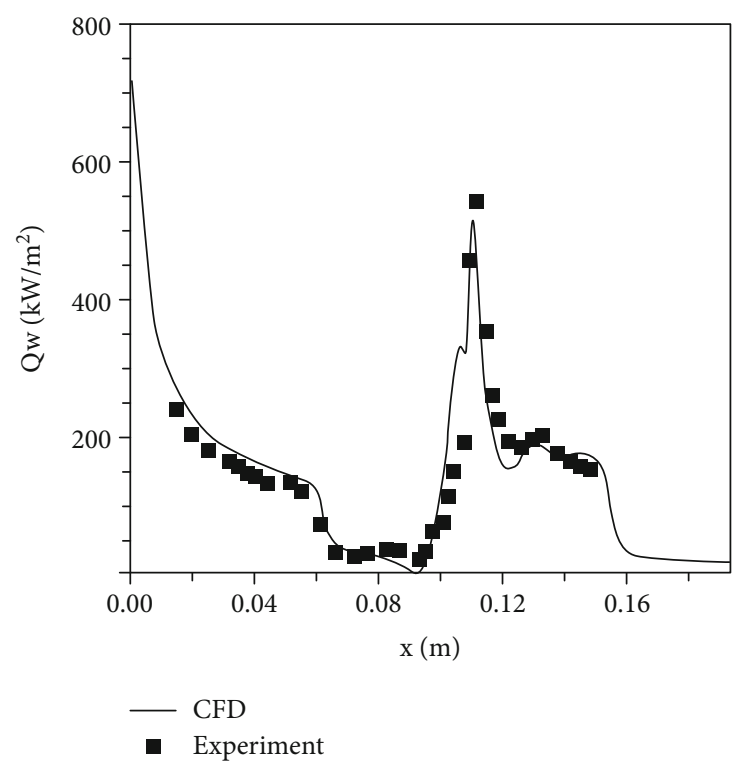

FIGURE 3: Distribution of heat-flux on double-cone wall surface.

simulation method is involved to recognize the characteristics of interaction flow and profile of thermal environment on the shield of Mars Lander.

\section{Numerical Simulation Method}

The protrusion interaction thermal environment of the Mars capsule is analyzed by solving NS equations for multicomponent chemical reaction in this paper. The equations are solved through discretization based on the finite volume method, the spatial discretization scheme is AUSM+ scheme which has higher computational accuracy [7], and the time discretization scheme is LUSGS scheme. In calculation, thermo nonequilibrium and chemical nonequilibrium hypotheses are introduced; viscosity, conductivity, and diffusion models are given according to the methods for solving the integral of collision cross-sections with reference to 


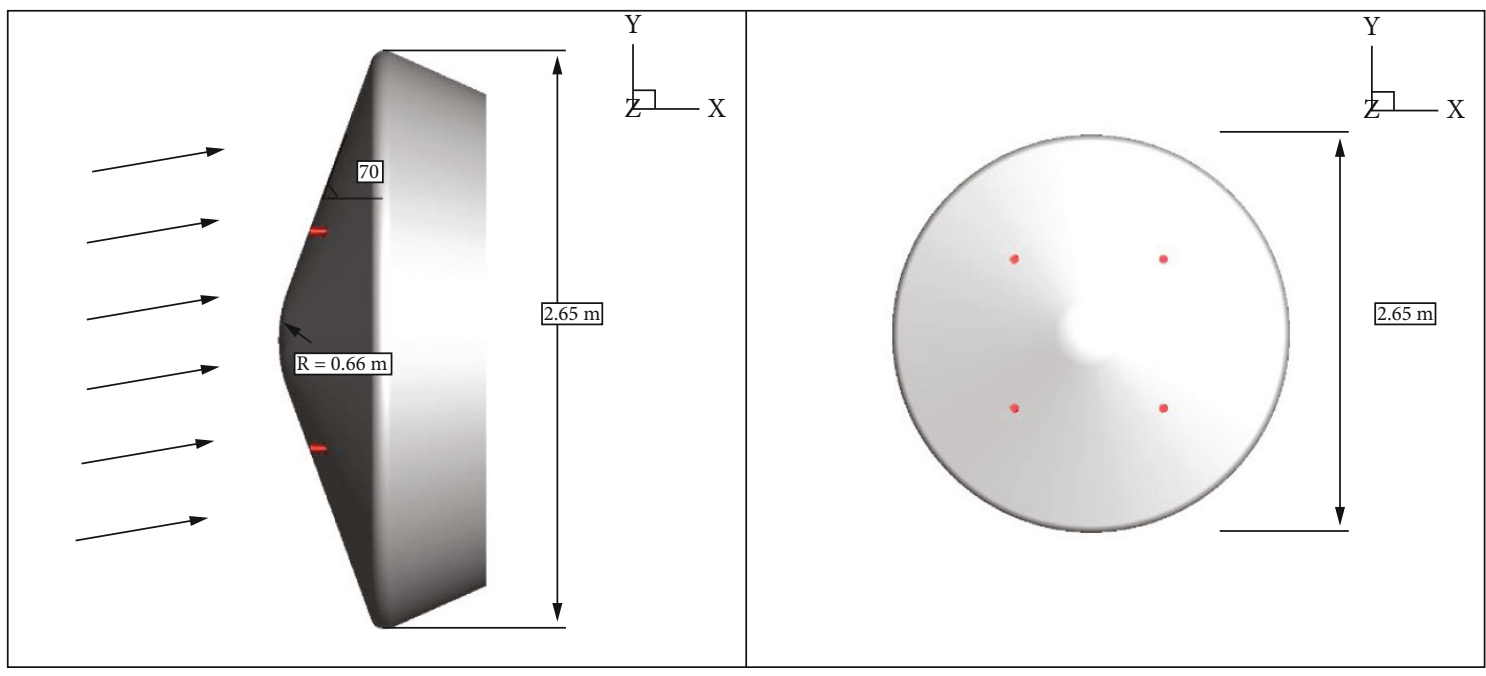

Figure 4: Outline of the capsule and location of titanium pipes.

literature [8]. For chemical reaction models, because the atmosphere of Mars concludes $97 \% \mathrm{CO}_{2}$ and $3 \% \mathrm{~N}_{2}$, eight components and nine reaction models mentioned in literature [9] are used, and the components involved are $\mathrm{O}, \mathrm{O}_{2}$, $\mathrm{CO}_{2}, \mathrm{CO}, \mathrm{C}, \mathrm{N}, \mathrm{N}_{2}$, and NO. In the process of computation, set $T_{w}$ (temperature of the surface) $=300 \mathrm{~K}$ and choose a fully catalytic wall as a condition of the surface. For thermodynamic nonequilibrium models, a two-temperature model is used, where $T$ represents translational temperature and rotational temperature and $T_{V}$ represents vibration temperature and electron temperature, and translation-vibration energy relaxation models are taken into account. See literature [10] for specific models.

2.1. Validation and Verification. First, Mars Pathfinder [11] entry vehicle is selected as the subject of verification, and the comparison with data on heat flux of the shield included in multiple literatures has verified the ability of this method to simulate the flow of Mars entry. In this verification, only the heat flux on the surface of the shield is compared. The state of calculation is $M=32, T=169 \mathrm{~K}, T_{w}=2100 \mathrm{~K}$, and $\rho=2.8 \times 10^{-4} \mathrm{~kg} / \mathrm{m}^{3}$. The comparison of the calculation results in this paper with the heat flux in the literatures at the fully catalytic wall condition is shown in Figure 1. The distribution of heat flux on the shield is essentially consistent, and the stagnation-point heat flux $\left(109 \mathrm{~W} / \mathrm{cm}^{2}\right)$ is slightly smaller than the stagnation-point heat flux in the literatures $\left(111.8 \mathrm{~W} / \mathrm{cm}^{2}\right)$.

Candler [12] 25-55 angle double-cone typical compressioncorner interaction experiment is selected as the subject of verification to verify the ability of this method to simulate the thermal environment of complex shock wave boundary-layer interaction region. Mach number of inflow $M a=11.3$, temperature $T=138.9 \mathrm{~K}$, density $\rho=0.552 \mathrm{~kg} / \mathrm{m}^{3}$, and temperature of the surface $T_{w}=300 \mathrm{~K}$.

The contours of temperature and pressure at plane of symmetry are shown in Figure 2. It can be seen that a remarkable separation and shock wave structure are located at the corner. The comparison of the thermal environment
TABLE 1: Flow conditions.

\begin{tabular}{lccc}
\hline Height $(\mathrm{km})$ & Speed $(\mathrm{m} / \mathrm{s})$ & Temperature $(\mathrm{K})$ & Angle of attack \\
\hline 80 & 6000 & 131.9 & 10 \\
60 & 5400 & 144.7 & 10 \\
\hline
\end{tabular}

on the surface of the wall with the experimental data is shown in Figure 3, and both match well with each other. The separation region, dramatic decline caused by expansion, and quick rise of heat flux resulting from separation and reattachment can be observed, and the size of the separation region and the peak heat-flux at the separation region are captured accurately.

2.2. Analysis of Interaction Thermal Environment. With Pathfinder as an example, interaction thermal environment around the protuberances on the surface of the Mars capsule shield is studied in this paper. The parameters of the outline of Pathfinder are shown in Figure 4, including the direction of flows and the schematic diagram of location of titanium pipes. The titanium pipes are $70 \mathrm{~mm}$ in height, about $40 \mathrm{~mm}$ in diameter, located at four generatrices of 45,135,225 and 315, and $700 \mathrm{~mm}$ away from the central vertex.

Two typical flow conditions are analyzed. Two specific calculation conditions are listed in Table 1. The two flight conditions have the same angle of attack, so their flow structures are similar. Interaction flow structure and thermal environment at the condition of $H=80 \mathrm{~km}$ are analyzed as an example.

The distribution of the flow fields in the interaction region of the titanium pipe and its nearby streamlines is shown in Figure 5. At this point, the angle of attack is 10 degrees, and there is significant difference between streamlines in the proximity of the titanium pipe Y1 in the windward area and the titanium pipe B1 in the leeward area. The flow at the titanium pipe B1 is dominated by boundary-layer flow that evolves from the stagnant flow and creates apparent characteristics of boundary- 

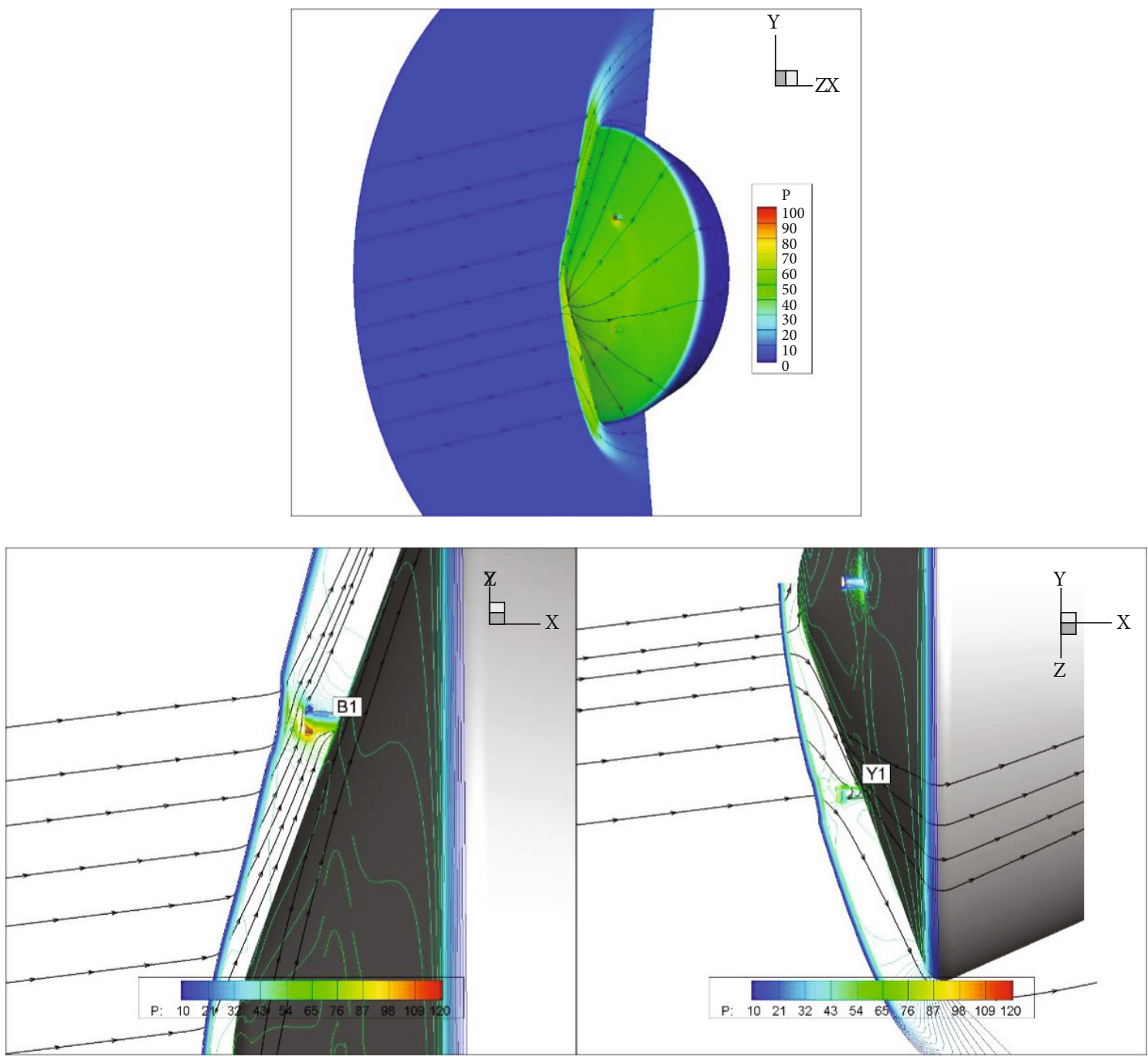

FIgURe 5: Parameters of the flow field in the proximity of the titanium pipe and distribution of streamlines of flow around blunt body.

layer flow on the surface of the titanium pipe. The flow at the titanium pipe B1 mainly develops from outside of the local shock layer and exhibits remarkable characteristics of stagnant flow. This can be observed more clearly from the angle between the direction of the flow before the titanium pipes $\mathrm{B} 1$ and $\mathrm{Y} 1$ and the axis line of the titanium pipe. As the axis line of the titanium pipe is parallel to the $x$-axis and the semicone angle of the shield is 70 degrees, at this point, the angle between the direction of flow in front of the titanium pipe $\mathrm{B} 1$ and the axis line of the titanium pipe is about 65 degrees, which means the direction of flow is basically parallel to the conical surface; the angle between the direction of flow velocity in front of the titanium pipe Y1 and the axis line of the titanium pipe is about 45 degree, which means that the direction of flow and the conical surface form an angle of attack with around 25 degrees.

From the research of Hung et al. [1,2] on protrusion interaction, it can be seen that the protrusion interaction thermal environment in the hypersonic flow field is mainly influenced by inflow Mach number, Reynolds number, and the height of the protuberance, especially the relative height of the protuberance to the boundary layer. If the protuberance is above the thickness of the boundary layer, external flow will cause stronger interaction to the protuberance; if the protuberance is hidden in the boundary layer, the interaction will be decreased significantly.

The Mach number isopleths for the cross-section of the protrusions of two titanium pipes $(\mathrm{Ma}=1)$ is shown in Figure 6. It can be seen that, at the titanium pipe B1, most areas of the titanium pipe are in the flow field with Mach number more than 1 , while at the titanium pipe Y1, the entire titanium pipe is in the flow field with Mach number less than 1. Therefore, it can be concluded that the interaction flow at the titanium pipe B1 on the leeward location is significantly stronger than that at the titanium pipe $\mathrm{Y} 1$ on the windward location, thus causing stronger interaction heating at B1. This deviates from the general idea that the heating in the windward area is stronger than that in the leeward area.

The contours of pressure and heat-flux in the interaction regions of two titanium pipes are shown in Figure 7. It can be seen that the peak heat-flux at the titanium pipe mainly locates at the upper end of the titanium pipe, and the 


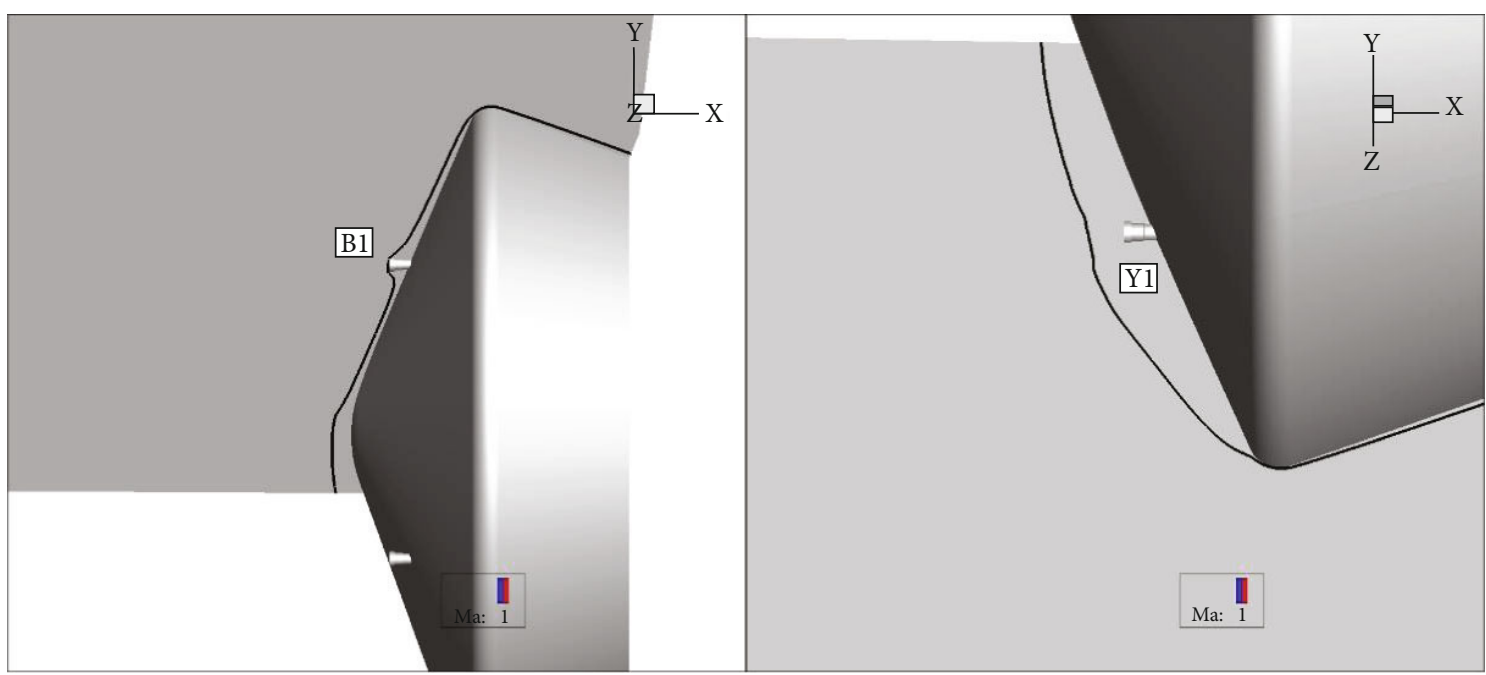

FIGURE 6: Isopleths at the titanium pipe on different locations $(\mathrm{Ma}=1)$.
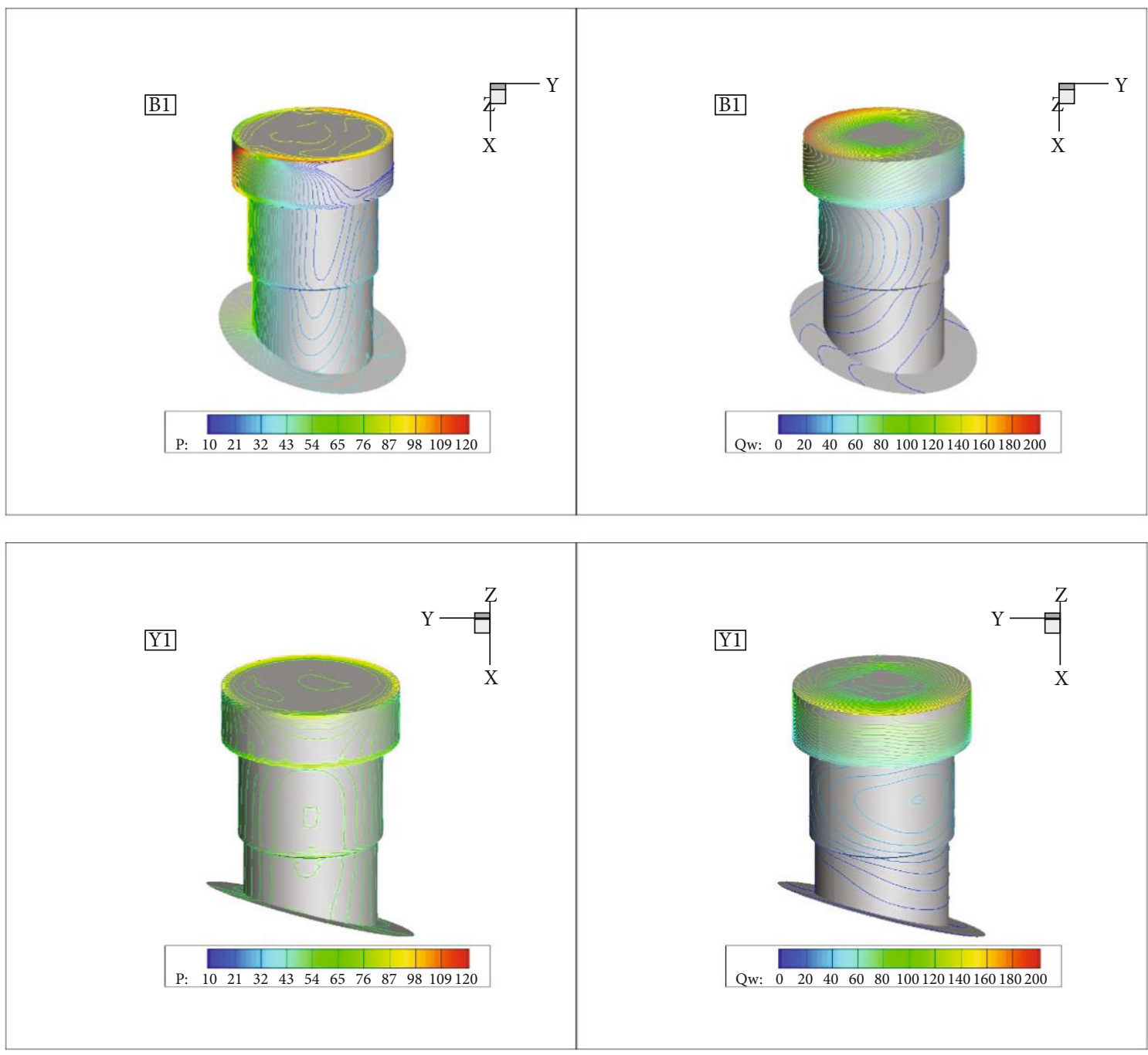

FIgURE 7: Distribution of pressure and heat flux on the surface of different titanium pipes. 


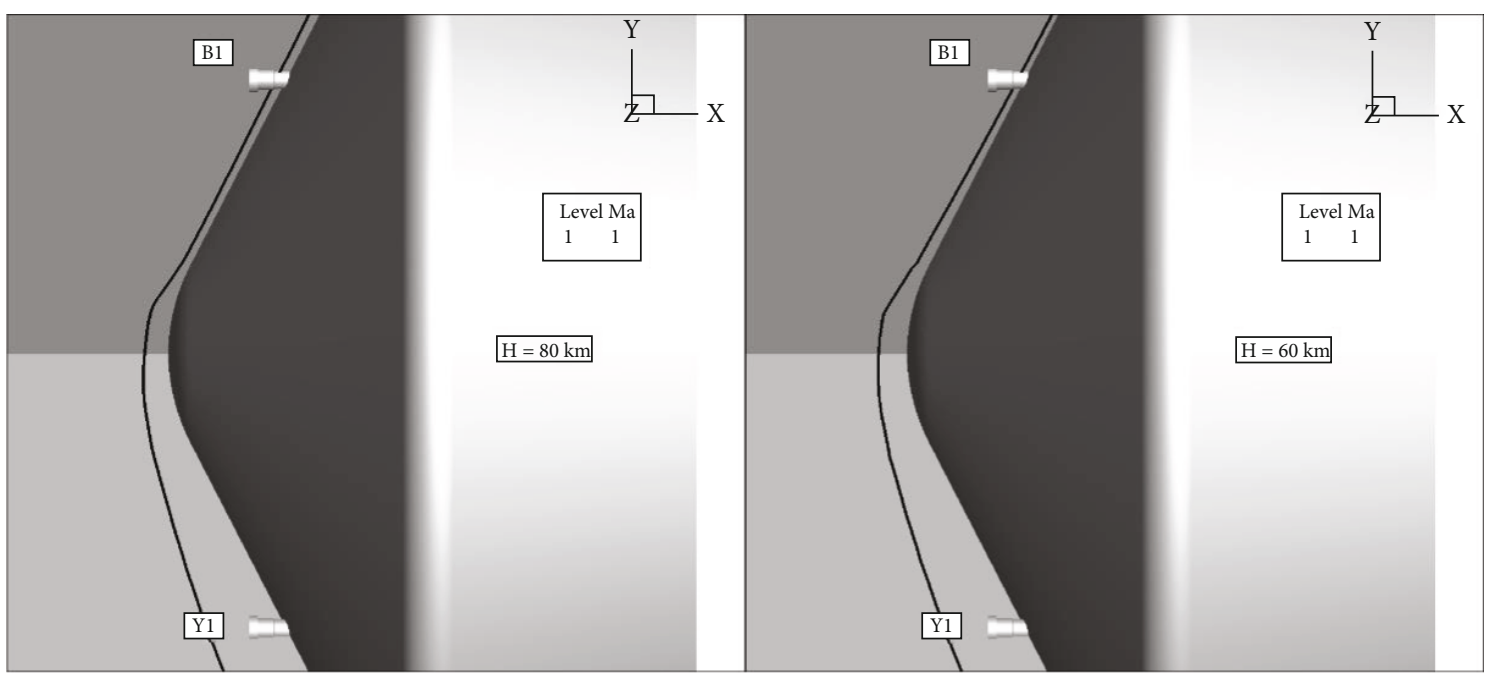

Figure 8: Distributions of isopleths at the titanium pipes on different heights $(\mathrm{Ma}=1)$.
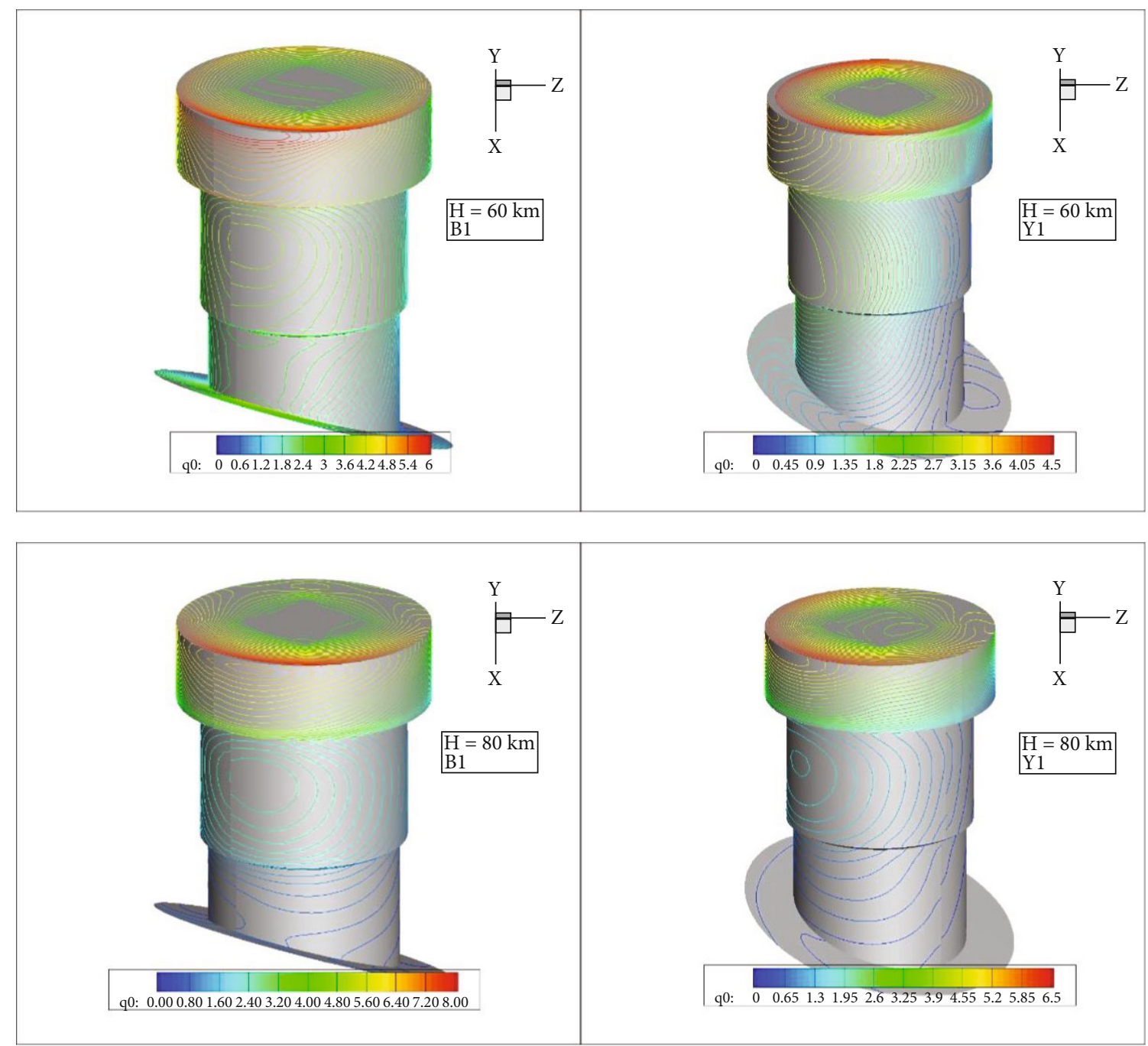

Figure 9: Distributions of dimensionless heat flux on the titanium pipes. 
interaction thermal environment of the titanium pipe $\mathrm{Y} 1$ is significantly smaller than that of the titanium pipe B1. As the titanium pipe $\mathrm{B} 1$ is dominated by boundary-layer flow, there is a noticeable high-pressure, high-temperature area in the windward side of the titanium pipe, in addition to the high-pressure, high-temperature area on the top of the titanium pipe. For the titanium pipe Y1, the high-pressure, high-temperature area is mainly on the top of the titanium pipe and the pressure and heat-flux on the cylindrical segment decrease significantly. The peak heat-flux of the titanium pipe $\mathrm{B} 1$ is about $180 \mathrm{~kW} / \mathrm{m}^{2}$, and the peak heat-flux of the titanium pipe $\mathrm{B} 1$ is about $150 \mathrm{~kW} / \mathrm{m}^{2}$.

Although the angles of attack at different heights are consistent, flow Mach number and Reynolds number in different flight conditions vary greatly, and the thermal environment in the interference area of the titanium pipe will be different due to the individual flight conditions. Whether the local Mach number is more than 1 or not is the important basis for judging the strength of flow interference at this location. It is also possible to analyze flow interaction that could occur locally through the total enthalpy boundary layer of flow field. The distributions of isopleths Ma equal to 1 around the titanium pipe at different flight conditions are shown in Figure 8. It can be seen that for different flight conditions, velocities vary greatly, but the characteristics of flow in the interaction area of the titanium pipe are consistent. The windward titanium pipe is dominated by stagnant flow, and the leeward titanium pipe is dominated by shear flow. The heights at the windward and leeward titanium pipes $(\mathrm{Ma}=1)$ are $160 \mathrm{~mm}$ and $12 \mathrm{~mm}$, respectively, when $H=60 \mathrm{~km}$; the heights at the windward and leeward titanium pipes $(\mathrm{Ma}=1)$ are $160 \mathrm{~mm}$ and $15 \mathrm{~mm}$, respectively, when $H=80 \mathrm{~km}$.

The distributions of dimensionless heat-flux on the surface of the titanium pipes at two flight conditions are shown in Figure 9. Dimensionless heat-flux is the ratio of interaction heat-flux to the local noninteraction heat-flux. At the flight condition of $H=80 \mathrm{~km}$ and $H=60 \mathrm{~km}$, noninteraction heat-flux of the shield are $22 \mathrm{~kW} / \mathrm{m}^{2}$ and $50 \mathrm{~kW} / \mathrm{m}^{2}$. Although interaction thermal environment at the titanium pipe $(H=80 \mathrm{~km})$ is lower, dimensionless heat flux there is bigger.

\section{Conclusions}

In this paper, the mechanism of protrusion interaction thermal environment on the surface of the Mars entry capsule was studied, the characteristics of flow at the typical flow conditions were derived by means of numerical simulations, and its generation mechanism and distribution rules were analyzed. The results show that:

For the Mars entry capsule, there is difference between interaction flow mechanisms of the titanium pipes at different locations on the shield. The titanium pipe in the windward area is dominated by strong subsonic compression stagnant flow, and the titanium pipe in the leeward area is dominated by supersonic boundary-layer shear flow. Therefore, the interaction flow of the titanium pipe in the leeward area is stronger, and the interference thermal environment is severe.

The titanium pipe B1 is dominated by boundary-layer flow. In addition to high-pressure, high-temperature areas on the top of the titanium pipe, there are remarkable highpressure, high-temperature areas in the windward side of the titanium pipe. For the titanium pipe Y1, the high-pressure, high-temperature areas are mainly on the top of the titanium pipe, and the pressure and heat-flux at the cylindrical segment are reduced significantly.

At the flight condition of $H=80 \mathrm{~km}$, noninteraction heat-flux is lower than flight condition of $H=60 \mathrm{~km}$, but the dimensionless heat-flux on the surface of the titanium pipe is higher.

\section{Data Availability}

Some or all data, models, or code generated or used during the study are proprietary or confidential in nature and may only be provided with restrictions.

\section{Disclosure}

The views and conclusions contained herein are those of the authors and should not be interpreted as necessarily representing the official policies or endorsements.

\section{Conflicts of Interest}

The authors declare that they have no competing interests.

\section{Authors' Contributions}

The corresponding author is Miao Wenbo who contributed to the literature review, data analysis, the writing of paper, and the revision of the paper. The second author and the third author contributed to the data acquisition, the data analysis, and the writing of the paper. The fourth author contributed to validation of method and the writing of the paper. The fifth author contributed to the calculation planning and proofreading of the paper. The authors read and approved the final manuscript.

\section{Acknowledgments}

This work was sponsored by the thermal protection system research mission of TianWen Mars Exploration Project of China and Joint Funds of National Natural Science Foundation of China (no. U20B2017).

\section{References}

[1] F. T. Hung, "Three-dimensional protuberance interference heating in high speed flow," in 18th Aerospace Sciences Meeting, Pasadena,CA,U.S.A, 1980.

[2] R. Sedney and C. W. Kitchens, "Separation ahead of protuberances in supersonic turbulent boundary layers," AIAA Journal, vol. 15, no. 4, pp. 546-552, 1977.

[3] M. S. Holden, "A study of flow separation in regions of shock wave boundary layer interaction in hypersonic flow," in 11th 
Fluid and PlasmaDynamics Conference, Seattle,WA,U.S.A, 1978.

[4] L. Suxun, Complex flow dominated by shock waves and boundary layers, Science Press, Beijing, 2007.

[5] H. Pan, "Analysis on thermal environment of interaction region around protuberance in high speed flows," Chinese Journal of Computational Physics, vol. 30, no. 6, pp. 825-832, 2013.

[6] L. Fuqun, "A study on characters of hypersonic multiprotuberance disturber," Structure \& Environment Engineering, vol. 45, no. 1, pp. 12-18, 2018.

[7] M. S. Liou, "A further development of the AUSM+ scheme towards robust and accurate solutions for all speeds," in 16th AIAA Computational Fluid Dynamics Conference, Orlando, Florida, 2013.

[8] P. A. Gnoffo, R. N. Gupta, and J. LShinn, Conservation equations and physical models for hypersonic air flows in thermal and chemical non-equilibrium, NASA TP, 1989.

[9] C. Park, J. T. Howe, and R. L. Jaffe, "Review of chemical-kinetic problems of future NASA missions, II: Mars entries," Journal of Thermo-physics and Heat Transfer, vol. 8, no. 1, pp. 9-23, 1994.

[10] M. Wenbo, "A study on the influence of thermodynamic model on the thermal environment of Mars reentry," Chinese Journal of Computational Physics, vol. 32, no. 4, pp. 410-415, 2015.

[11] K. Sutton and R. A. Graves, A general stagnation-point convective-heating equation for arbitrary gas mixtures, NASA TR, 1990.

[12] G. V. Candler, "CFD validation for hypersonic flight: hypersonic double-cone flow simulations," in 40th AIAA Aerospace Sciences Meeting \& Exhibit, Reno,NV,U.S.A, 2002. 